\title{
O ensino do processo de enfermagem no contexto da Pandemia da Covid- 19
}

\author{
Luciana Regina Ferreira da Mata \\ (D) 0000-0002-5080-4643 \\ Escola de Enfermagem da Universidade Federal de Minas Gerais (EEUFMG). \\ E-mail: lucianamata@ufmg.br
}

O mundo vivencia diversos desafios impostos pela pandemia da Covid-19 causada pelo coronavírus (SARS-CoV-2), visto que dados relativos ao número de casos positivos, hospitalizações e mortes mudam a todo o momento ${ }^{1}$.

Esta crise sanitária não tem apenas um impacto aos envolvidos na linha de frente e aos líderes clínicos, mas a todos os sistemas e comunidades. A pandemia da COVID-19 também impactou mudanças nas universidades e nos sistemas de ensino.

No campo da saúde, as escolas de enfermagem debatem e buscam preparo para as barreiras relacionadas à formação da próxima geração de profissionais. O processo de ensino em enfermagem aponta preocupações tanto para educadores quanto para os estudantes face à pandemia da COVID-19². Com o agravamento da pandemia, têm se questionado: como continuar a educar enfermeiros numa sociedade que enfrenta medidas de distanciamento social, isolamento e quarentena?

No que tange ao processo de enfermagem, promover o seu aprendizado por meio de tecnologias à distância pode ser considerado desafiador. A condução do ensino das etapas do processo de enfermagem requer a proposição de estratégias pedagógicas que desenvolvam habilidades relacionadas ao raciocínio clínico em enfermagem. E, no contexto da impossibilidade da vivência prática e do contato com o paciente, definir estratégias que facilitem a aquisição de habilidades intelectuais para reconhecimento de pistas ou evidências clínicas, bem como para diferenciação de uma situação clínica de outra semelhante têm sido foco de discussão entre educadores em enfermagem.

O desenvolvimento do raciocínio clínico está relacionado a diversos fatores: aquisição de conhecimento teórico, prática clínica, tempo de vivência em ambiente clínico, bom senso e capacidade de julgamento/raciocínio3 ${ }^{3}$ Diante da pandemia da Covid-19 foi necessária a suspensão do ensino prático o que, consequentemente, comprometeu a oferta de elementos essenciais para formação da capacidade de tomada de decisões clínicas em enfermagem.

Um exemplo de impacto do distanciamento social no ensino das etapas do processo de enfermagem é a condução de aulas relacionadas ao exame físico, que envolve a etapa de coleta de dados. Técnicas semiológicas de inspeção, palpação, percussão e ausculta requerem habilidades manuais e instrumentais que podem ser alcançadas a partir de treinamento eficiente associado ao manuseio de equipamentos auxiliares à execução do exame físico, como estetoscópio, esfigmomanômetro, otoscópio, entre outros. Contudo, sem acesso a equipamentos e ao toque humano no contexto clínico, assegurar o aprendizado da etapa de coleta é um problema posto.

O domínio da técnica é relevante para o sucesso na execução do exame físico, mas é preciso considerar também toda a subjetividade que surge durante a interação paciente e profissional, visto que o cuidado, sensível e científico, intrínsecos à enfermagem não dissociam da técnica e da tecnologia ${ }^{4}$. E, frente à pandemia da Covid-19 nos deparamos com a impossibilidade de desenvolver as habilidades provenientes da interação paciente-discente.

É importante ressaltar que esse conhecimento subjetivo e objetivo que envolve o exame clínico é a base para a formulação de hipóteses diagnósticas. Portanto, além do conhecimento relacionado à coleta de dados, é preciso refletir sobre como ensinar os conceitos de interesse para disciplina de enfermagem, 
denominados diagnósticos de enfermagem, por meio da tecnologia à distância. Essa é a base de conhecimento necessária para que a partir da junção de dados coletados seja possível formular o diagnóstico de enfermagem, visto que sem o domínio do raciocínio diagnóstico as consequentes etapas do processo de enfermagem perdem o sentido.

Outra vertente a ser discutida sobre o ensino do processo de enfermagem no contexto remoto é a disposição das tecnologias digitais e a capacidade de acesso e de uso das ferramentas tanto pelo docente quanto pelo discente. É preciso refletir que, para o sucesso do processo ensino-aprendizagem de conteúdos teóricos, docentes precisam ser capacitados para o intermédio efetivo do conteúdo por meio das plataformas virtuais, de forma a compreender e a usufruir de recursos que potencializem a interação e a orientação do ensino. Do mesmo modo, discentes também precisam ter acesso, capacidade e disponibilidade para operacionalizar tais ferramentas virtuais.

Assim, diante do distanciamento social posto pela pandemia, como podemos lançar mão de estratégias pedagógicas para conduzir o ensino do processo de enfermagem? Dentre algumas possibilidades, têm-se o trabalho com pequenos grupos virtuais a partir de vídeos de simulação clínica que caracterizam um cenário para coleta de dados, estudos de casos fictícios para ensino do raciocínio diagnóstico, e a implementação de jogos virtuais para estabelecer feedback do conteúdo apreendido ao final das aulas.

Essa discussão não se encerra. Neste momento, é comum termos mais perguntas do que respostas, mas a partilha destas preocupações permite reflexão e tomadas de decisões coletivas frente ao processo ensinoaprendizagem. Diante desses duradouros meses de pandemia da Covid-19 fica também uma certeza de que é possível mediar o ensino de alguns conteúdos por meio de ferramentas virtuais. Todavia, a interação humana e o contato físico que se dão por meio da prática clínica são imprescindíveis para consumação do aprendizado do processo de enfermagem.

\section{Referências}

1 - Coronavirus disease 2019 (COVID-19) Situation Report - 66 [Internet] Who.int.2021 [cited 2021 May 14]. Available at: https://www.who.int/teams/integrated-health-services/patientsafety/policy/global-patient-safety-action-plan

2 - Dewart G, Corcoran L, Thirsk L, Petrovic K. Nursing education in a pandemic: Academic challenges in response to COVID-19. Nurse Educ Today [Internet]. 2020 Sep [cited 2021 May 14];92:104471. Available at: https://www.ncbi.nlm.nih.gov/pmc/articles/PMC7263267/ doi: 10.1016/i.nedt.2020.104471

3 - Carvalho EC de, Oliveira-Kumakura AR de S, Morais SCRV. Clinical reasoning in nursing: teaching strategies and assessment Rev Bras Enferm [Internet]. 2017 Jun [cited 2021 May 17];70(3):662-8. Available at: https://www.scielo.br/scielo.php?script=sci_arttext\&pid=S003471672017000300662\&lng=en.\%20\%20 https://doi.org/10.1590/0034-7167-2016-0509

4 - Silva CMC da, Sabóia VM, Teixeira ER. O ensino do exame físico em suas dimensões técnicas e subjetivas. Texto contexto - enferm [Internet]. 2009 Sep [cited 2021 May 14];18(3):458-65. Available at: https://www.scielo.br/scielo.php?script=sci_arttext\&pid=\$0104-07072009000300008\&lng=en https://doi.org/10.1590/S0104-07072009000300008

\section{Como Citar este Editorial:}

Mata LRF. O ensino do processo de enfermagem no contexto da Pandemia da Covid- 19. Revista de Enfermagem do

Centro-Oeste Mineiro. 2021;10: e4438. [Access___] Available_in:__. DOI:

